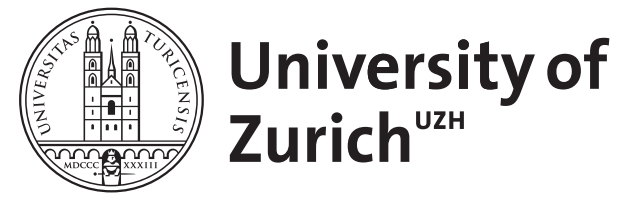

Zurich Open Repository and Archive

University of Zurich

University Library

Strickhofstrasse 39

CH-8057 Zurich

www.zora.uzh.ch

Year: 2007

\title{
Gefitinib concentrations in human glioblastoma tissue
}

Hofer, Silvia ; Frei, Karl

DOI: https://doi.org/10.1007/s11060-006-9257-3

Posted at the Zurich Open Repository and Archive, University of Zurich

ZORA URL: https://doi.org/10.5167/uzh-155718

Journal Article

Published Version

Originally published at:

Hofer, Silvia; Frei, Karl (2007). Gefitinib concentrations in human glioblastoma tissue. Journal of NeuroOncology, 82(2):175-176.

DOI: https://doi.org/10.1007/s11060-006-9257-3 


\title{
Gefitinib concentrations in human glioblastoma tissue
}

\author{
Silvia Hofer · Karl Frei
}

Received: 1 August 2006/Accepted: 25 August 2006/Published online: 29 September 2006

(C) Springer Science+Business Media B.V. 2006

Delivery of anticancer agents to solid tumors is not well investigated and studies analyzing drug concentrations in human tumor tissue, especially in the brain, are scarce.

In our institution, we have the opportunity to directly measure anticancer drug concentrations in glioblastoma (GBM) tumor tissue in correlation to plasma concentration. GBM patients with a relapse, however in good performance status are offered secondary surgery where appropriate and participation in a prospective trial with gefitinib [1]. Gefitinib is currently under scrutiny for the treatment of high grade glioma [2].

At least 5 days before re-operation, patients receive gefitinib $500 \mathrm{mg}$ daily continuously until tumor progression or intolerable side effects. Patients on cytochrome P450 isoenzyme CYP3A4-inducing antiepileptic drugs (EIAE) have to change to a nonenzyme-inducing drug, due to predicted ensuing interactions of EIAE with gefitinib metabolism, reducing its systemic availability. The trial is approved by the local ethic committee and is registered within the National Library of Medicine Clinical Trials Database (www.clinicaltrials.gov, NCT00250887).

S. Hofer $(\bowtie)$

Medical Oncology, University Hospital Zürich, Rämistrasse 100, 8091 Zürich, Switzerland

e-mail: silvia.hofer@usz.ch

K. Frei

Department of Neurosurgery, University Hospital Zürich,

Zürich, Switzerland
Table 1 Gefitinib tumor and plasma concentrations

\begin{tabular}{lrl}
\hline Pat. No. & GBM tissue $(\mathrm{ng} / \mathrm{g})$ & Plasma $(\mathrm{ng} / \mathrm{ml})$ \\
\hline $1^{*}$ & 24103 & na \\
$1^{*}$ & 8681 & na \\
$1^{*}$ & 11103 & na \\
2 & 3132 & 247 \\
3 & 4963 & 176 \\
4 & 6218 & 181 \\
5 & 2852 & 4 \\
6 & 4730 & 127 \\
7 & 3468 & 176 \\
\hline
\end{tabular}

na: not assessed

*All three samples of this patient were collected on the same occasion

Here we report on surprisingly high tumor tissue levels of gefitinib from the first seven patients (Table 1). Tumor tissue and blood samples were snap frozen immediately upon removal and stored at $-70^{\circ} \mathrm{C}$ for analysis (Laboratory Analytico Medinet B.V., Breda, NL). High performance liquid chromatography coupled to tandem mass spectroscopy was performed to determine drug concentrations, as described previously [3].

To our knowledge this is the first consecutive series of gefitinib concentrations in human brain tumor tissue. We suggest, that higher drug exposure is not required to treat glioma patients.

Further translational research will be performed with the tumor material to correlate responding patients to their tumor EGFR pathway activity and to define molecular markers predictive for response. 


\section{References}

1. Hofer S, Frei K, Rutz HP (2006) Gefitinib accumulation in glioblastoma tissue. Cancer Biol Ther 5:483-484

2. Uhm JH, Haas-Kogan DA, Mischel PS (2006) Epidermal growth factor receptor in glioma: biology, prognosis and clinical trials. In: Educational book, Am Soc Clin Oncol, pp 85-91
3. Zhao M, Hartke C, Jimeno A et al (2005) Specific method for determination of gefitinib in human plasma, mouse plasma and tissues using high performance liquid chromatography coupled to tandem mass spectrometry. J Chromatogr B Analyt Technol Biomed Life Sci 819:73-80 